\title{
Cut off values for abdominal obesity as a criterion of metabolic syndrome in an ethnic Kyrgyz population (Central Asian region)
}

\author{
Aibek E Mirrakhimov ${ }^{1,2^{*}}$, Olga S Lunegova ${ }^{2}$, Alina S Kerimkulova', Cholpon B Moldokeeva ${ }^{1}$, Malik P Nabiev ${ }^{1}$ and \\ Erkin M Mirrakhimov ${ }^{1,2}$
}

\begin{abstract}
Background: People of different racial and ethnic backgrounds have a distinct pattern of central fat deposition, thus making it necessary to devise a race based approach for the diagnosis and evaluation of abdominal obesity (AO). This is the first study to determine the optimal waist circumference (WC) cutoff values for definition of AO in an ethnic Kyrgyz population.

Methods: 323 persons of Kyrgyz ethnicity (183 women and 140 men), with a mean age of $51.8 \pm 9.5$ years old were included in the study. Measurement of blood pressure (BP), anthropometric data (including body mass index calculation and WC measurement), fasting blood sugar, serum lipid parameters and insulin were performed in all examined individuals. Insulin resistance (IR) was considered as HOMA index (insulin $\times$ fasting glucose/22.5) $\geq 2.77$. Sensitivity and specificity for the presence of IR or two other criteria of MS (according to the international classification, 2009) were calculated by using receiver operating characteristic (ROC) curves for men and women separately.
\end{abstract}

Results: The optimal sensitivity and specificity obtained from the ROC curves for IR were $88 \mathrm{~cm}$ in women (sensitivity of $0.85,95 \% \mathrm{Cl}(0.72-0.93)$, specificity of $0.58,95 \% \mathrm{Cl}(0.49-0.66)$ ) and $94 \mathrm{~cm}$ for men (sensitivity of $0.8,95 \%$ $\mathrm{Cl}(0.65-0.91)$, specificity of $0.61,95 \% \mathrm{Cl}(0.51-0.71))$. The data from the ROC curve for any two other MS criteria confirmed the results and the WC $88 \mathrm{~cm}$ in women (sensitivity of $0.82,95 \% \mathrm{Cl}(0.72-0.9)$, specificity of $0.72,95 \% \mathrm{Cl}$ $(0.62-0.8))$ and $94 \mathrm{~cm}$ in men (sensitivity of $0.74,95 \% \mathrm{Cl}(0.62-0.84)$, specificity of $0.73,95 \% \mathrm{Cl}(0.61-0.83)$ ) were corresponded to the optimal sensitivity and specificity.

Conclusion: WC $\geq 88 \mathrm{~cm}$ and $\geq 94 \mathrm{~cm}$ should be used as a criterion for the diagnosis of AO for Kyrgyz women and men respectively based on these results.

Keywords: Obesity, Abdominal obesity, Waist circumference insulin resistance, Metabolic syndrome, Cardiovascular risk

\section{Background}

Metabolic syndrome (MS) is a particularly common medical condition consisting of abdominal obesity (AO), arterial hypertension, as well as disturbances in lipid and/or carbohydrate metabolism. The presence of MS increases cardiovascular morbidity and mortality and risk of future type 2 diabetes mellitus (DM) [1,2].

\footnotetext{
* Correspondence: amirrakhimov1@gmail.com

'Kyrgyz State Medical Academy named by I.K. Akhunbaev, Akhunbaev street 92, Bishkek 720020, Kyrgyzstan

Full list of author information is available at the end of the article
}

Obesity is believed to be a core pathologic stimulus for the development of hyperinsulinemia and insulin resistance (IR), which are predictive for the development of new onset type 2 DM [3]. Obesity is also associated with increased cardiovascular risk, but with age this association seems to fade [4].

Several clinical approaches for MS diagnosis are currently available such as, Adult Treatment Panel (ATP III) of the National Cholesterol Education Program [5] and its modified version [6] use waist circumference (WC) of $\geq 88 \mathrm{~cm}$ and $\geq 102 \mathrm{~cm}$ for the diagnosis of $\mathrm{AO}$

\section{Ciomed Central}


in women and men respectively. Since ATP III clinical criteria are best suitable for North American population, and the fact that people of Asian origin have higher abdominal fat with the same body mass index (BMI) as well as a greater risk for the new onset type $2 \mathrm{DM}$ with the same BMI values and this approach may underestimate metabolic risk among Asians [7]. Dong and colleagues have found the greater accuracy of height to weight ratio for the diagnosis of MS compared to traditional measurement of WC in a Chinese population [8]. Interestingly, Park and colleagues have demonstrated that Asians with BMI $<27 \mathrm{~kg} / \mathrm{m} 2$ have higher predictive power of epicardial fat for the presence of MS and coronary artery disease, which may indirectly support the notion of distinct pattern of adiposity among Asians [9].

The controversies of current clinical models for diagnosing MS were highlighted in the secondary analysis of the FIELD study [10]. The researchers compared three different criteria for MS: World Health Organization, ATP III and International Diabetes Federation. They have concluded that WHO MS criteria can identify patients with DM who have a lower risk of future cardiovascular events.

There are some misconceptions regarding the optimal WC values and methods of assessing this in some Asian populations [11,12]. A recent Joint Interim Statement on MS proposes that $W C \geq 80 \mathrm{~cm}$ and $\geq 90 \mathrm{~cm}$ are diagnostic for AO in Asian women and men respectively [13]. However such generalization may be wrong due to possible heterogeneities among Asian populations. Thus, the need for different diagnostic criteria based on ethnic background was critically needed.

The information about optimal WC values for MS diagnosis was not known for the Kyrgyz ethnic group, and this became a cardinal impetus for the study.

\section{Methods}

\section{Studied population}

323 individuals (183 females, 140 males) $30-80$ years (mean age $51.8 \pm 9.5$ years) from the general population were included in the study. Informed consent was signed prior to enrollment. Exclusion criteria: pregnancy, concomitant thyroid disease, heart failure, chronic kidney and liver disease, insulin therapy and chronic alcohol addiction.

Systolic and diastolic blood pressure (SBP and DBP respectively) measurements, anthropometric assessment such as weight, height were measured in all study participants. WC was measured in the standing relaxed position, during expiration, at the midline between the lower costal margins and the iliac crest parallel to the floor. Body mass index (BMI) was calculated as a weight $(\mathrm{kg})$ to height $\left(\mathrm{m}^{2}\right)$ ratio.

The general characteristics of studied population are present in Table 1.
Table 1 General characteristics of studies population

\begin{tabular}{|c|c|}
\hline Variables & Study participants (n - 323) \\
\hline Age; years & $51.8 \pm 9.5$ \\
\hline $\mathrm{AH} ; \mathrm{n}(\%)$ & $133(41.2 \%)$ \\
\hline SBP: $\mathrm{mm} \mathrm{Hg}$ & $135.2 \pm 21.8$ \\
\hline $\mathrm{DBP} ; \mathrm{mm} \mathrm{Hg}$ & $85.5 \pm 12.5$ \\
\hline Obesity (BMI $\left.\geq 30 \mathrm{~kg} / \mathrm{m}^{2}\right) ; \mathrm{n}(\%)$ & $97(30 \%)$ \\
\hline $\mathrm{BMl} ; \mathrm{kg} / \mathrm{m}^{2}$ & $27.5 \pm 4.8$ \\
\hline$W C ; \mathrm{cm}$ & $91.7 \pm 11.5$ \\
\hline Smoking; n (\%) & $48(14.9 \%)$ \\
\hline Positive family history for CVD; $\mathrm{n}(\%)$ & $73(22.6 \%)$ \\
\hline Type 2 DM; n (\%) & $25(7.7 \%)$ \\
\hline Fasting glucose; mmol/l & $5.92 \pm 1.83$ \\
\hline Insulin resistance; n (\%) & $88(27.2 \%)$ \\
\hline Serum insulin; $\mu \mathrm{IU} /\left.\mathrm{m}\right|^{*}$ & $7.25(4.89-10.6)$ \\
\hline HOMA index* & $1.85(1.18-2.99)$ \\
\hline CHD; n (\%) & $28(8.7 \%)$ \\
\hline $\mathrm{TC} ; \mathrm{mmol} / \mathrm{l}$ & $5.12 \pm 1.11$ \\
\hline $\mathrm{HDL}-\mathrm{C} ; \mathrm{mmol} / \mathrm{l}$ & $1.14 \pm 0.34$ \\
\hline LDL-C; mmol/l & $3.27 \pm 0.96$ \\
\hline $\mathrm{TG} ; \mathrm{mmol} / /^{*}$ & $1.24(0.95-1.92)$ \\
\hline
\end{tabular}

*Data is presented as median (25\%-75\%); Abbreviations: AH-arterial hypertension, BMI-body mass index, CHD-coronary heart disease, CVD cardiovascular diseases, DBP-diastolic blood pressure, DM- diabetes mellitus, HDL-C-high density cholesterol, IR-insulin resistance, LDL-C-low density cholesterol, SBP-systolic blood pressure, TC-total cholesterol, TG-triglycerides, WC-waist circumference

\section{Laboratory tests}

Blood collection from the cubital vein took place after $12 \mathrm{~h}$ of fasting in the morning, with further separation to the plasma and serum, which were frozen in liquid nitrogen. Subsequently laboratory tests such as fasting plasma glucose (FPG), total cholesterol (TC), triglycerides (TG), high density lipoprotein cholesterol (HDL-C) and immunoreactive insulin levels were analyzed from the frozen blood samples. Low density lipoprotein cholesterol (LDLC) was calculated by Friedwald W. formula [14]. Homeostasis model of assessment (HOMA) was used as a surrogate marker of IR and calculated as serum insulin $(\mu \mathrm{IU} / \mathrm{ml}) \times$ plasma glucose $(\mathrm{mmol} / \mathrm{l}) / 22.5$. HOMA index $\geq 2.77$ was considered to be diagnostic for IR, according to the results from the Bruneck study [15].

\section{Statistical analysis}

The "Microsoft-Statistica 8.0" and "Graph Pad PRIZM 5" software were used for statistical analyses. ANOVA according to Kruskal-Wallis method was used to compare the IR values (given the nonparametric distribution of variables). A posthoc comparison of variables was measured by the Mann-Whitney test with Bonferroni correction. Odds ratio (OR) and $95 \%$ confidence interval (CI) were calculated using the " $2 \times 2$ tables" in the "Graph Pad PRIZM 5" program. Receiver-Operating Characteristic (ROC) analysis was performed with the 
construction of ROC curves to identify the borderline WC values. Variables are present as mean \pm standard deviation for normal distribution and median (25\%-75\%) for variables with nonparametric distribution. The $\mathrm{p}$ value $<0.05$ was used as a cut off for statistical significance.

\section{Results}

To define the threshold values for WC, the entire data set (separately for men and women) was divided into subgroups with WC increments of 4-5 cm. Common borderline values from the modified ATP III criteria $(\geq 102 \mathrm{~cm}$ in men and $\geq 88 \mathrm{~cm}$ in women), the International diabetes Federation (IDF) criteria ( $\geq 94 \mathrm{~cm}$ in men and $\geq 80 \mathrm{~cm}$ in women) and the IDF criteria for the Asian population ( $\geq$ $90 \mathrm{~cm}$ in men and $\geq 80 \mathrm{~cm}$ in women) were taken into consideration. Thus, women were subdivided based on the WC values into subgroups of $<80 \mathrm{~cm}, 80-87 \mathrm{~cm}$, and $\geq 88$ $\mathrm{cm}$; and men were subdivided into these subgroups $<90$ $\mathrm{cm}, 90-93 \mathrm{~cm}, 94-101 \mathrm{~cm}, \geq 102 \mathrm{~cm}$.

After this, each subgroup was analyzed for the presence of IR, blood insulin concentration, the HOMA index and the OR of having IR. A greater WC was associated with an increased likelihood for IR in both women and men. Women with $\mathrm{WC} \geq 88 \mathrm{~cm}$ had 2.5 times increased prevalence of IR compared to the WC of $80-87 \mathrm{~cm}$. $23 \%$ of men with WC $\geq 90 \mathrm{~cm}$ had IR, whereas $28 \%$ of men with WC of 94-101 cm had IR. $60 \%$ of men with WC $\geq 102$ $\mathrm{cm}$ had IR, which was expected. However statistical significance was observed only for the subgroup with WC of $94-101 \mathrm{~cm}$.

The gradual statistically significant increase of HOMA index and blood insulin concentration was found in association with the increase in WC for all groups. Neither men nor women experienced jumps in HOMA index or insulin concentration.

Greater OR for IR were associated with the increase in WC. Statistically significant differences in OR for IR were observed between the first and third women subgroups. Whereas differences between the first and second women subgroups were close to statistical significance. Men had statistically significant differences in OR for IR compared to men with $W C<90 \mathrm{~cm}$. The OR for IR increased in men with WC of $94-101 \mathrm{~cm}$, but compared to the WC of $90-93 \mathrm{~cm}$ the difference was not significant (Tables 2 and 3).

During the construction of ROC curves, women with WC of $80 \mathrm{~cm}$ had a sensitivity of $98 \%$, but relatively low specificity of $32 \%$. Whereas women with WC of $88 \mathrm{~cm}$ had specificity of $58 \%$ and sensitivity of $85 \%$ (Figure 1 ).

In an analogous analysis, men with WC of $90 \mathrm{~cm}$ had a sensitivity of $95 \%$ and relatively low specificity of $49 \%$. Men with WC of $94 \mathrm{~cm}$ had greater specificity of $61 \%$ and sensitivity $80 \%$, and men with WC of $102 \mathrm{~cm}$, had specificity of $90 \%$, but the sensitivity was markedly decreased and reached 46\% (Figure 2).

Current clinical guidelines do not include IR as the MS criteria. Therefore, we also conducted ROC analysis to identify the threshold WC values, which increase the risk for detection of any two other MS criteria (BP $\geq 130 / 85$ $\mathrm{mm} \mathrm{Hg}$, fasting blood sugar $\geq 5,6 \mathrm{mmol} / \mathrm{l}$, HDL-C in men $<1.03 \mathrm{mmol} / \mathrm{l}$ and in women $<1.29 \mathrm{mmol} / \mathrm{l}$, TG 1.7 $\mathrm{mmol} / \mathrm{l})$.

The results of this analysis were almost the same as during the ROC analysis for the IR. Thus, for women with WC of $80 \mathrm{~cm}$ the sensitivity was nearly $100 \%$, but

Table 2 IR indexes according to WC in women

\begin{tabular}{llllll}
\hline Subgroups & $\mathbf{W C} ; \mathbf{c m}$ & $\mathbf{I R} ; \mathbf{n}(\mathbf{\%})$ & Insulin concentration & HOMA $^{\mathbf{5}}$ & OR $(\mathbf{9 5} \% \mathbf{C l})$ \\
\hline 1 & $<80(\mathrm{n}-41)$ & $1(2.4)$ & $4.49(2.83-5.92)$ & $1.03(0.63-1.43)$ & 1 \\
\hline 2 & $80-87(\mathrm{n}-40)$ & $6(15)$ & $6.74^{*}(5.39-8.41)$ & $1.64^{*}(1.21-1.96)$ & $7.05(0.8-61.6) \mathrm{P}_{1-2}=0.057$ \\
\hline 3 & $\geq 88(\mathrm{n}-102)$ & $40(39)^{* \#}$ & $9.04^{* *}(7.10-14.0)$ & $2.46^{* \#}(1.79-3.71)$ & $26(3.4-19.5) \mathrm{P}_{1-3}<0.0001 \mathrm{P}_{2-3}<0.005$ \\
\hline & $\mathrm{P}$ & $<0.00001$ & $<0.0001$ & $<0.0001$ & \\
\hline
\end{tabular}

\$- Data is presented as median (25\%-75\%);

* $p<0.0001$ as compared with 1 subgroup; \#p $<0.0001$ as compared with 2 subgroup Abbreviations: OR-odds ratio

Table 3 IR indexes according to WC in men

\begin{tabular}{|c|c|c|c|c|c|}
\hline Subgroups & WC; cm & IR; n (\%) & Insulin concentration $\$$ & HOMA $^{\$}$ & OR $(95 \% \mathrm{Cl})$ \\
\hline 1 & $<90(n-44)$ & $2(4.2)$ & $3.85(2.69-6.87)$ & $0.95(0.65-1.65)$ & 1 \\
\hline 2 & 90-93 (n-21) & $5(23)$ & $6.03(5.14-7.05)$ & $1.49(1.30-2.08)$ & $6.56(1.15-3.73) P_{1-2}<0.01$ \\
\hline 3 & $94-101(n-35)$ & $10(28)^{*}$ & $7.41 *(5.32-10.91)$ & $1.87^{*}(1.38-3.04)$ & $8.4(1.7-4.15) P_{1-3}<0.003$ \\
\hline \multirow[t]{2}{*}{4} & $\geq 102(n-40)$ & $24(60) * \# \underline{1}$ & $10.7^{* \# E}(8.3-15.65)$ & $3.14^{* \# E}(2.17-4.81)$ & $31.5(6.66-14.9) \mathrm{P}_{1-4}<0.0001 \mathrm{P}_{2-4} 001 \mathrm{P}_{3-4}<0.005$ \\
\hline & $P$ & $<0.00001$ & $<0.0001$ & $<0.0001$ & \\
\hline
\end{tabular}

\$-Data is presented as median (25\%-75\%)

${ }^{*} \mathrm{P}<0.0001$ as compared with 1 subgroup; \#P $<0.0001$ as compared with 2 subgroup; $£ \mathrm{P}<0.0001$ as compared with 3 subgroup 


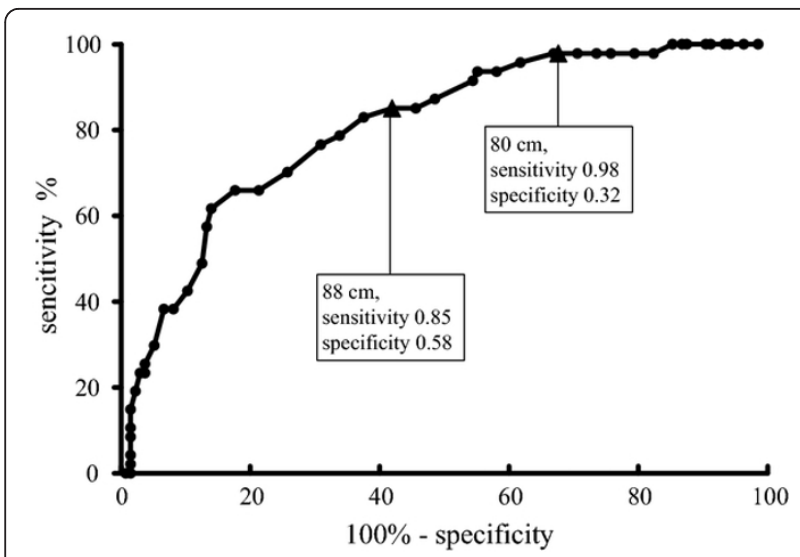

Figure 1 Sensitivity and specificity for the presence of IR according to WC increase in women (ROC curve).

specificity was only $45 \%$. Women with $\mathrm{WC}$ of $88 \mathrm{~cm}$ had a moderate decrement in sensitivity to $82 \%$, and increase in specificity to $72 \%$ (Figure 3 ).

In men with the WC of $90 \mathrm{~cm}$ a fairly high specificity (63\%) was noted, which was increased to $73 \%$ in men with WC of $94 \mathrm{~cm}$ and men with WC of $102 \mathrm{~cm}$ had specificity of $89 \%$. Men with WC of $94 \mathrm{~cm}$ had moderately decreased sensitivity of $74 \%$, and men with WC of $102 \mathrm{~cm}$ experienced a sharp drop in sensitivity to $30 \%$ (Figure 4).

\section{Discussion}

The data regarding the definition of AO based on ethnic and racial guidelines is controversial. US Caucasians have increased cardiovascular risk with $\mathrm{WC} \geq 102 \mathrm{~cm}$ and $\geq 88$ $\mathrm{cm}$ for men and women respectively. Whereat, African Americans have borderline WC of 89 to $109 \mathrm{~cm}$ for men and from 83 to $105 \mathrm{~cm}$ for women respectively, due to a

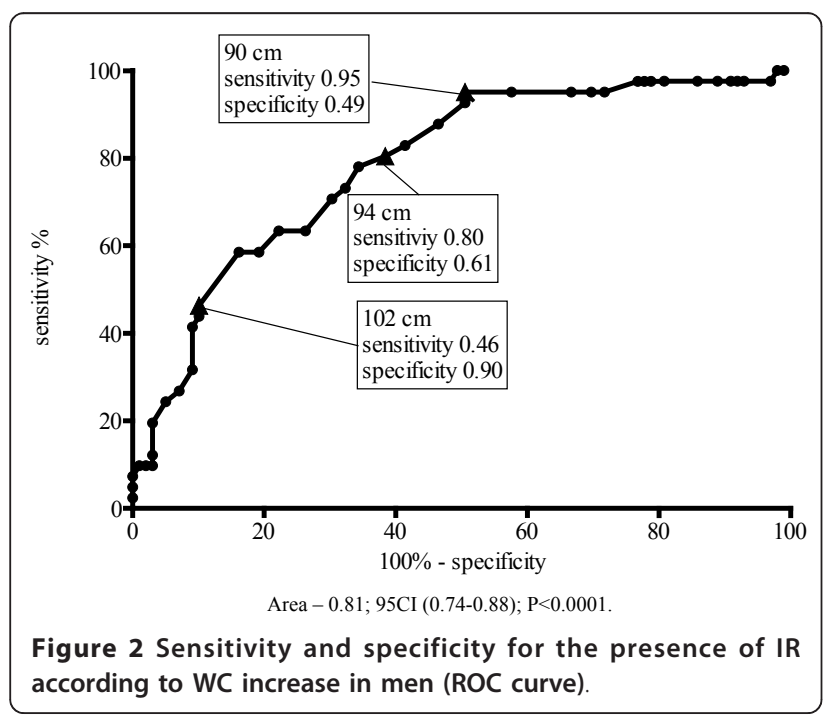

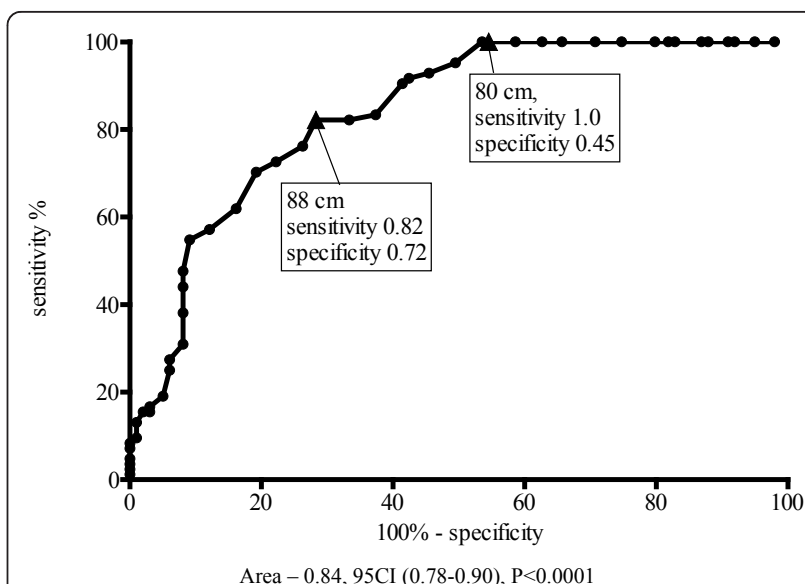

Figure 3 Sensitivity and specificity for detection of two MS criteria in women (ROC curve)

lower amount of visceral fat with the same BMI [16-18]. Since African Americans have a higher prevalence of cardiovascular risk factors it was believed to use a similar WC cut off. The similar conclusions were made for indigenous American population [19].

The same is true regarding borderline WC values for Europeans. Accordingly to some studies, the risk of new onset type $2 \mathrm{DM}$ development increases from $\mathrm{WC} \geq 94 \mathrm{~cm}$ and $\geq 80 \mathrm{~cm}$ in men and women respectively [20-22].

The studies on Asian populations have shown that Asians have a higher level of visceral fat within the same BMI values compared to Caucasians [23,24].

In India, where type $2 \mathrm{DM}$ and IR are highly prevalent $[24,25]$, the researchers have found that the risk of type $2 \mathrm{DM}$ started to rise from $\mathrm{BMI}>23 \mathrm{~kg} / \mathrm{m} 2$ and $\mathrm{WC}>$ $85 \mathrm{~cm}$ in men and WC > 80 in women [26,27]. The optimal WC values of $\geq 85 \mathrm{~cm}$ for men and $\geq 80 \mathrm{~cm}$ for

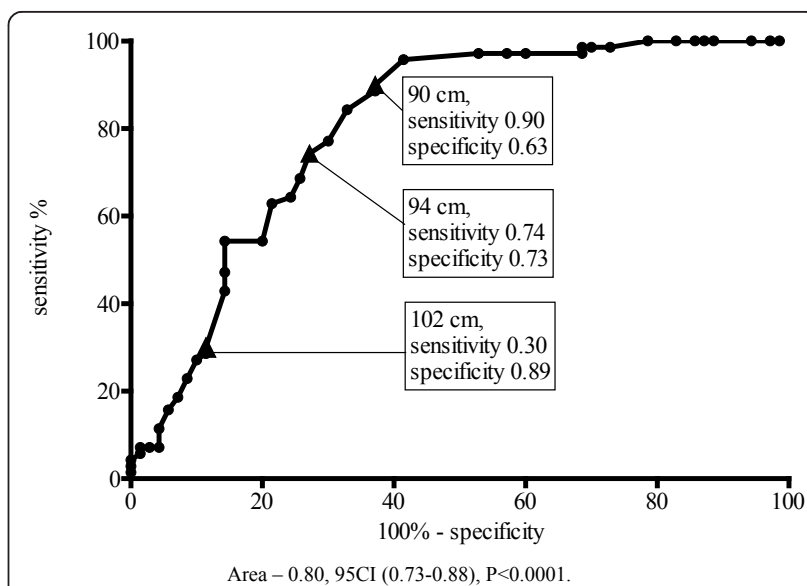

Figure 4 Sensitivity and specificity for detection of two MS criteria in men (ROC curve). 
women of Chinese descent were found after pooling the results of 13 population studies [28].

Similar studies were performed in Japan where borderline WC values of 85 to $90 \mathrm{~cm}$ for men and $>80 \mathrm{~cm}$ for women were found [29]. In an ethnic Korean population, the borderline WC ranges from 85 to $90 \mathrm{~cm}$ in men and from 80 to $85 \mathrm{~cm}$ in women [30-32]. The borderline WC values of $99.5 \mathrm{~cm}$ for men and $94.3 \mathrm{~cm}$ were found for Iranians aged 19-65 years [33].

Controversies on the optimal definition of the AO according to the racial and ethnic background are still present. Our data may be extrapolated on nearby Central Asian indigenous groups, such as Kazakhs, Uzbeks and Turkmens and help to resolve some of the current difficulties in this area. Nevertheless studies with a larger population sample are critically needed to find the optimal definition for AO in Central Asian population groups. This approach can significantly increase the accuracy for the diagnosis of $\mathrm{AO}$, which is a key criterion for the diagnosis of MS. Thus it can potentially decrease the healthcare burden of this disease through appropriate lifestyle and medical intervention in a proper time.

\section{Conclusion}

This is the first study to determine the optimal WC cut off values for an ethnic Kyrgyz population. WC $\geq 88 \mathrm{~cm}$ and $\geq 94 \mathrm{~cm}$ should be used as a criterion for the diagnosis of AO for Kyrgyz women and men respectively based on these results.

\begin{abstract}
Abbreviations
AO: Abdominal obesity; ATP: Adult treatment panel; BMI: Body mass index; DBP: Diastolic blood pressure; DM: Diabetes mellitus; FPG: Fasting plasma glucose; HDL-C: High density lipoprotein cholesterol; HOMA: Homeostasis model of assessment; IDF: International diabetes federation; IR: Insulin resistance; LDL-C: Low density lipoprotein cholesterol; MS: Metabolic syndrome; ROC: Receiver operating characteristic; SBP: Systolic blood pressure; TC: Total cholesterol; TG: Triglycerides; WC: Waist circumference.
\end{abstract}

\section{Author details}

'Kyrgyz State Medical Academy named by I.K. Akhunbaev, Akhunbaev street 92, Bishkek 720020, Kyrgyzstan. ${ }^{2}$ National Centre of Cardiology and Internal medicine named by M. Mirrakhimov, T. Moldo 3, Bishkek 720040, Kyrgyzstan.

\section{Authors' contributions}

All authors contributed equally in the patient evaluation and article draft composition. AEM and OSL performed statistical analysis of the data. EMM edited the manuscript for content and AEM revised it and translated into English. All authors read and approved the final manuscript.

\section{Competing interests}

The authors declare that they have no competing interests.

Received: 5 December 2011 Accepted: 22 February 2012 Published: 22 February 2012

\section{References}

1. Lakka HM, Laaksonen DE, Lakka TA, Niskanen LK, Kumpussalo E, Tuomilehto J, Salonen JT: The metabolic syndrome and total and cardiovascular disease mortality in middleaged men. JAMA 2002, 288:2709-2716.

2. Schmidt MI, Duncan BB, Bang H, Pankow JS, Ballantyne CM, Folsom AR, Chambless LE: Identifying individuals at high risk for diabetes: The Atherosclerosis Risk in Communities study. Diabetes Care 2005, 28:2013-2018.

3. Sung $\mathrm{KC}$, Seo MH, Rhee EJ, Wilson AM: Elevated fasting insulin predicts the future incidence of metabolic syndrome: a 5-year follow-up study. Cardiovasc Diabetol 2011, 10:108.

4. Wakabayashi I, Daimon T: Receiver-operated characteristics (ROCs) of the relationships between obesity indices and multiple risk factors (MRFs) for atherosclerosis at different ages in men and women. Arch Gerontol Geriatr 2011.

5. National Cholesterol Education Program (NCEP) Expert Panel on Detection, Evaluation, and Treatment of High Blood Cholesterol in Adults (Adult Treatment Panel III). Third Report of the National Cholesterol Education Program (NCEP) Expert Panel on Detection, Evaluation, and reatment of High Blood Cholesterol in Adults (Adult Treatment Panel III) final report. Circulation 2002, 106:3143-3421.

6. Grundy SM, Cleeman Jl, Daniels SR, Donato KA, Eckel RH, Franklin BA, Gordon DJ, et al: Diagnosis and management of the metabolic syndrome: an American Heart Association/National Heart, Lung and Blood Institute scientific statement. Curr Opin Cardiol 2006, 21:1-6.

7. Alberti KG, Zimmet P, Shaw J: IDF Epidemiology Task Force Consensus Group. The metabolic syndrome: a new worldwide definition. Lancet 2005, 366:1059-1062.

8. Dong X, Liu Y, Yang J, Sun Y, Chen L: Efficiency of anthropometric indicators of obesity for identifying cardiovascular risk factors in a Chinese population. Postgrad Med J 2011, 87:251-256.

9. Park JS, Ahn SG, Hwang JW, Lim HS, Choi BJ, Choi SY, Yoon MH, Hwang GS, Tahk SJ, Shin JH: Impact of body mass index on the relationship of epicardial adipose tissue to metabolic syndrome and coronary artery disease in an Asian population. Cardiovasc Diabetol 2010, 9:29.

10. Scott R, Donoghoe M, Watts GF, O'Brien R, Pardy C, Taskinen MR, Davis TM, Colman PG, Manning P, Fulcher G, Keech AC: Impact of metabolic syndrome and its components on cardiovascular disease event rates in 4900 patients with type 2 diabetes assigned to placebo in the FIELD randomised trial. Cardiovasc Diabetol 2011, 10(1):102.

11. Yokoyama H, Hirose H, Kanda T, Kawabe H, Saito I: Relationship between waist circumferences measured at the umbilical level and midway between the ribs and iliac crest - a solution to the debate on optimal waist circumference standards in the diagnostic criteria of metabolic syndrome in Japan. J Atheroscler Thromb 2011, 18:735-743.

12. Das M, Pal S, Ghosh A: Prevalence of the metabolic syndrome in people of Asian Indian origin: outcomes by definitions. Cardiovasc J Afr 2011, 22:303-305.

13. Alberti MM, Eckel RH, Grundy SM, Zimmet PZ, Cleeman JI, Donato KI, et al: Harmonizing the Metabolic Syndrome: A Joint Interim Statement of the Association for the Study of Obesity Heart Federation; International Atherosclerosis Society; and International National Heart, Lung, and Blood Institute; American Heart Association; World International Diabetes Federation Task Force on Epidemiology and Prevention. Circulation 2009, 120:1640-1645.

14. Fridewald WT, Levy RI, Fredrickson DS: Estimation of the concentration of low density lipoprotein cholesterol in plasma, without use of the preparative ultracentrifuge. Clin Chem 1972, 18:499-502.

15. Bonora E, Kiechl S, Willeit J, Oberhollenzer F, Egger G, Targher G, Alberiche M, Bonadonna RC, Muggeo M: Prevalence of insulin resistance in metabolic disorders: the Bruneck Study. Diabetes 1998, 47:1643-1649.

16. Deurenberg $P$, Yap M, van Staveren WA: Body mass index and percent body fat: a meta-analysis among different ethnic groups. Int I Obes Relat Metab Disord 1998, 22:1164-1171.

17. Diaz VA, Mainous AG III, Baker R, Carnemolla M, Majeed A: How does ethnicity affect the association between obesity and diabetes? Diabet Med 2007, 24(11):1199-1204.

18. Zhu S, Heymsfield SB, Toyoshima H, Wang Z, Pietrobelli A, Heshka S: Raceethnicity-specific waist circumference cutoffs for identifying cardiovascular disease risk factors. Am J Clin Nutr 2005, 81:409-415.

19. Lear SA, James PT, Ko GT, Kumanyika S: Appropriateness of waist circumference and waist-to- hip ratio cutoffs for different ethnic groups. Eur J Clin Nutr 2010, 64:42-61. 
20. Lean J, Han TS, Morrison CE: Waist circumference as a measure for indicating need for weight management. BMJ 1995, 311(6998):158-161.

21. Lean J, Han TS, Seidell JC: Impairment of health and quality of life in people with large waist circumference. Lancet 1998, 351(9106):853-856.

22. Han TS, van Leer EM, Seidell JC, Lean J: Waist circumference action levels in the identification of cardiovascular risk factors: prevalence study in a random sample. BMJ 1995, 311(7017):1401-1405.

23. World Health Organization: Obesity: Preventing and Managing the Global Epidemic: Report on a WHO Consultation (WHO Technical Report Series 894. Geneva, Switzerland: World Health Organization; 2000.

24. Banerji MA, Faridi N, Atluri R, Chaiken RL, Lebovitz HE: Body composition, visceral fat, leptin and insulin resistance in Asian Indian men. J Clin Endocrinol Metab 1999, 84:137-144.

25. Chandalia M, Abate N, Garg A, Stray-Gundersen J, Grundy SM: Relationship between generalized and upper body obesity to insulin resistance in Asian Indian men. J Clin Endocrinol Metab 1999, 84:2329-2335.

26. Snehalatha C, Viswanathan V, Ramachandran A: Cutoff Values for Normal Anthropometric Variables in Asian Indian Adults. Diabetes Care 2003, 26(5):1380-1384

27. Mohan V, Deepa M, Farooq S, Narayan KM, Datta M, Deepa R. Anthropometric cut points for identification of cardiometabolic risk factors in an urban Asian Indian population. Metabolism 2007, 56(7):961-968.

28. Zhou BF: Cooperative Meta-Analysis Group of the Working Group on Obesity in China. Predictive values of body mass index and waist circumference for risk factors of certain related diseases in Chinese adults: study on optimal cut-off points of body mass index and waist circumference in Chinese adults. Biomed Environ Sci 2002, 15:83-96.

29. Examination Committee of Criteria for "Obesity Disease" in Japan; Japan Society for the Study of Obesity. New criteria for "obesity disease" in Japan. Circ J 2002, 66(11):987-992.

30. Lee SY, Park HS, Kim DJ, Han JH, Kim SM, Cho GJ, et al: Appropriate waist circumference cutoff points for central obesity in Korean adults. Diabetes Res Clin Pract 2007, 75:72-80.

31. Koh JH, Koh SB, Lee MY, Jung PM, Kim BH, Shin JY, et al: Optimal Waist Circumference Cutoff Values for Metabolic Syndrome Diagnostic Criteria in a Korean Rural Population. J Korean Med Sci 2010, 25:734-737.

32. Park YM, Kwon HS, Lim SY, Lee JH, Yoon KH, Son HY, et al: Optimal waist circumference cutoff value reflecting insulin resistance as a diagnostic criterion of metabolic syndrome in a nondiabetic Korean population aged 40 years and over: the Chungju Metabolic Disease Cohort (CMC) study. Yonsei Med J 2010, 51(4):511-518.

33. Heshmat R, Khashayar P, Meybodi HR, Homami MR, Larijani B: The appropriate waist circumference cut-off for Iranian population. Acta Med Indones 2010, 42(4):209-215.

doi:10.1186/1475-2840-11-16

Cite this article as: Mirrakhimov et al:: Cut off values for abdominal obesity as a criterion of metabolic syndrome in an ethnic Kyrgyz population (Central Asian region). Cardiovascular Diabetology 2012 11:16.

\section{Submit your next manuscript to BioMed Central and take full advantage of:}

- Convenient online submission

- Thorough peer review

- No space constraints or color figure charges

- Immediate publication on acceptance

- Inclusion in PubMed, CAS, Scopus and Google Scholar

- Research which is freely available for redistribution 